\title{
HABITAÇÃO, POLÍTICAS PÚBLICAS E DIREITO AO DESENVOLVIMENTO
}

\section{HOUSING, PUBLIC POLICIES AND THE RIGHT TO DEVELOPMENT}

Recebido: 15.08.2017

Aprovado: 29.09.2017

Giovana Ferro de Souza Roriz*

Resumo: Este artigo discorre sobre a habitação enquanto instrumento de política pública voltada para o desenvolvimento, visitando alguns registros históricos dos seus variados aspectos; discorrendo, por meio de revisão bibliográfica, sobre a habitação e demonstrando, por meio da experiência brasileira, a realização do desenvolvimento por meio de uma política pública de habitação com participação popular.

Palavras-chave: Habitação. Políticas Públicas. Desenvolvimento.

Abstract: This article reports on housing as an instrument of social policy towards the development, visiting historical records of its differents aspects; discussing, through a bibliographical review, about housing and showing, trough Brazilian experience, the achievement of development through a public policy of housing with popular participation.

Keywords: Housing. Social Policy. Development.

\section{INTRODUÇÃO}

O presente artigo tem por objetivo estudar o desenvolvimento e algumas de suas nuances, sem a pretensão, contudo, de exaurir a abordagem de tema bastante amplo.

A começar, no item 1 (um), pelo significado do próprio termo, o leitor será alertado para as variadas acepções da palavra "desenvolvimento", bem como ao fato de que o crescimento econômico, por si só, não é capaz de erradicar a pobreza.

Uma visitação a alguns registros históricos do desenvolvimento terá como ponto de partida o ano de 1945, tendo em vista que após a 2ª Guerra Mundial os abalos nos paradigmas econômicos se intensificaram de acordo com a velocidade dos avanços tecnológicos e da regulamentação dos direitos.

Nesse contexto, o "local" ganha os cenários mundial e nacional, enquanto são

\footnotetext{
* Doutora em Direito e Políticas Públicas pelo Centro Universitário de Brasília (UniCEUB); Mestre em Direito Agrário pela Universidade Federal de Goiás (UFG); Especialista em Direito Público pelo Axioma Jurídico em convênio com a Fesurv (Faculdade de Rio Verde-GO); Graduada em Direito pela Universidade Federal de Goiás (UFG); autora dos livros Atividade Agrária de Sequestro Florestal de Carbono e Audiência Pública na Jurisdição Ordinária pela Editora Lumen Juris. Analista judiciária do Tribunal de Justiça do Estado de Goiás (TJGO). E-mail: < giovanaferro@yahoo. com.br $>$.
} 
reformuladas as atividades do Estado, com destaque aos seus mais importantes papeis: o de gerenciador e fomentador.

Para garantir o desenvolvimento, é adotada a premissa de que cabe ao Estado uma série de deveres, dentre eles o de garantir a habitação enquanto direito humano fundamental.

O leitor é, então, convidado à análise, no item 2 (dois), da habitação enquanto dever do Estado, segundo os registros no cenário internacional e no ordenamento jurídico brasileiro, notadamente no âmbito da nossa ordem constitucional.

$\mathrm{O}$ item 3, é tópico específico sobre a realidade brasileira, voltados aos registros históricos nacionais da política de habitação; para, enfim, concluir que políticas públicas de habitação contribuem para o desenvolvimento segundo a literatura nacional e estrangeira.

\section{ANTECEDENTES HISTÓRICOS DA HABITAÇÃO ENQUANTO ASPECTO DO DIREITO AO DESENVOLVIMENTO NO BRASIL E NO MUNDO}

A divisão comum do mundo em países desenvolvidos e em desenvolvimento pressupõe o entendimento do significado da palavra desenvolvimento, podendo indicar, por exemplo, níveis de vida mais elevados; crescimento da capacidade produtiva; crescimento econômico; dentre outros (ARNDT, 1989, p.1).

Após a 2 ${ }^{\mathrm{a}}$ Guerra Mundial, o desenvolvimento se expressou, com maior intensidade, como sinônimo de crescimento econômico, até que, nos anos 6o (sessenta), foi identificada sua incapacidade, como tal, de erradicação da pobreza (ARNDT, 1989, p.3). A concepção de desenvolvimento, até então, era, portanto, equivocada: o crescimento econômico não era suficiente.

Em 1965, H. W. Singer publicou o artigo intitulado "Social Development: Key Growth Sector", no qual considerou que o problema dos países em desenvolvimento não era apenas crescimento, mas desenvolvimento como melhoria da qualidade de vida das pessoas: melhor saúde, melhor educação e melhor alimentação eram, para o autor, as chaves do crescimento (SINGER, apud ARNDT, 1989, p. 89 e 91).

De tal forma, nos anos 70 (setenta) operou-se um abalo dos paradigmas econômicos fortalecidos no pós-guerra: enquanto se consolidava o paradigma neoliberal dos mecanismos autorreguladores do mercado; exposições teóricas e experiências exitosas no campo com vistas à reestruturação dos processos produtivos indicaram as regiões como os novos âmbitos estratégicos no redirecionamento do desenvolvimento (FERNÁNDEZ, 2003, p.23).

Em outras palavras, as regiões se transformariam em complexos territoriais de acumulação flexível, ou seja, comunidades industriais conformadas a partir de processos de trabalho flexíveis, com forças de trabalho qualificadas, isto é, com alta capacidade de inovação e adaptação ao cenário global instável (FERNÁNDEZ, 2003, p.27).

Segundo Brandão,

[...] negando completamente a natureza das hierarquias (impostas em variadas escalas) de geração e apropriação de riqueza, segundo 
esse 'pensamento único' que invade o debate do desenvolvimento territorial, regional, urbano e local na atualidade, teria ocorrido o fim das escalas intermediárias (e das mediações) entre o local e o global. Se, por um lado, houve a revalorização do território, do que se convencionou chamar de 'geografia econômica', e da dimensão espacial do processo de desenvolvimento, por outro, ocorreu a completa banalização das questões que, malgrado sua natureza estrutural, histórica e dinâmica, foram deslocadas para o lugar-comum do voluntarismo, cristalizando um grande consenso, um verdadeiro 'pensamento único localista (2007, p. 35-36).

Ainda, nesse contexto, ao Estado pouco restaria fazer, limitando-se a ação pública ao provimento de externalidades positivas sobre as falhas de mercado (BRANDÃO, 2007, p. 46).

Essa perspectiva otimista, no entanto, foi confrontada com um novo elemento: a vulnerabilidade ou dificuldades de tipo estrutural das regiões, como problemas de escala para desenvolver níveis adequados de inovação; subdesenvolvimento no nível dos serviços; e dificuldades de ingresso nas redes globais de comercialização, pois altamente transnacionalizadas (FERNÁNDEZ 2003, p.42).

A organização da economia foi um dos principais constrangimentos ao avanço coletivo do bem-estar social, porquanto a primazia do ter regulou a relação entre o crescimento e a desigualdade social, de modo que $25 \%$ da população concentravam, por exemplo, $75 \%$ da produção mundial e menos que $0,2 \%$ da população mundial respondiam por cerca de 50\% da riqueza global (POCHMANN, 2000, p. 17).

Este cenário, representado por arquipélagos constituídos por um reduzido número de cidades que concentravam os serviços estratégicos da produção, mostram que os avanços ocorriam de forma geográfica muito concentrada (POCHMANN, 2000, p. 53).

No caso do Brasil, processos seculares legaram "uma 'fisionomia territorial' peculiar ao país, ressaltando duas características congênitas: a dimensão continental e as forças (mercantil e política) que contra-arrestarão o vigor centrífugo e dispersivo presente 'geneticamente' no país" (BRANDÃO, 2007, p. 90).

Nas palavras de Brandão,

[...] o processo histórico de desenvolvimento econômico brasileiro foi caracterizado noperíodoquevai da década de1930atéaproximadamente1970 por intenso processo de concentração econômica na região Sudeste, principalmente em São Paulo. O ano de 1970 apresentou o auge da concentração industrial. O Sudeste, naquele ano, respondia por $81 \%$ da produção industrial do país, sendo que São Paulo detinha $58 \%$ do total nacional. Outro dado ilustra a situação de região mais dinâmica do país concentradora não apenas da produção industrial, mas também da agrícola e terciária: em 1970, o Sudeste contribuía com dois terços do PIB brasileiro, sendo que São Paulo contribuía com 40\% (Cano, 1981). Durante a década de 1970, esse quadro de grande concentração industrial começou a mudar, afirmando-se o processo de desconcentração econômica para o interior de São Paulo e para as demais regiões do país (BRANDÃO, 2007, p. 135).

Em seguida, no final da década de 1970 e início da de 1980, a articulação e complementação dos sistemas nacionais de infraestrutura foram as marcas da ação 
do Estado brasileiro, com vistas à integração da diversidade econômica regional, com ampliação, por exemplo, da rede rodoviária (de $36.000 \mathrm{Km}$, sendo $13.803 \mathrm{Km}$ pavimentados, para $88.000 \mathrm{Km}$, sendo $47.000 \mathrm{Km}$ pavimentados) e da capacidade geradora instalada de energia elétrica (de 4.126 MW para 32.893 MW) (BRANDÃO, 2007, p. 138).

A intensa mobilidade territorial marcou a dinâmica do Brasil: zonas de atração e expulsão populacional afetaram as condições de vida das pessoas (POCHMANN, 2009, p.61), de modo que os números também indicaram que o Brasil experimentou um processo rápido, profundo e caótico de urbanização, porquanto:

[...] o país expulsou 28,6 milhões de habitantes do meio rural no período 19601980. Só na década de 1970 foram 15,6 milhões. Segundo Cano (1992), esses fatores determinaram que o processo de urbanização, antes 'suportável' (no período 1930-1960), chegasse aos níveis de verdadeira 'arrebentação urbana'. A taxa de crescimento da população urbana passou de 3,8\% a.a., no período 1940-1950, para 5,32\% a.a, entre 1950-1960, para 5,15\% a.a., no período 1960-1970, e chegou a 4,44\% a.a., entre 1970-1980. (...) Não apenas as áreas de grande concentração metropolitana vão conhecer tal processo caótico, mas inclusive as áreas 'beneficiadas' pela interiorização do desenvolvimento irão deparar-se com crescentes níveis de deterioração das condições de vida (BRANDÃO, 2007, p. 141-142).

Nessecontexto, a situação econômico-social seagravou, conformando uma crisedo padrão de sociabilidade, de modo que a pobreza urbana chamou a atenção, notadamente porque suas dimensões estavam associadas ao acesso precário à infraestrutura e aos serviços, aqui entendidos como abastecimento de água e saneamento, serviços de transporte, saúde, educação urbana, e habitação (HALL; MIDGLEY, 2008, p.120).

Segundo Piovesan,

[...] atualmente, cerca de $80 \%$ da população mundial vive em países em desenvolvimento. Dois deles - Índia e China - totalizam quase $1 / 3$ da população mundial. Contudo, os $15 \%$ mais ricos concentram $85 \%$ da renda mundial, enquanto os $85 \%$ mais pobres concentram apenas $15 \%$, sendo a pobreza a principal causa mortis do mundo. Instaura-se um círculo vicioso em que a desigualdade econômica fomenta a desigualdade política no exercício do poder no plano internacional e vice-versa (PIOVESAN, 2002).

Dessa forma, o debate acerca do desenvolvimento perpassou pelas limitações do crescimento econômico para, automaticamente, incluir "alternativas concretas de construção de cidadania, dignidade, segurança e proteção, com radicalidade democrática e redistribuição de renda, riqueza, poder e acesso ao Estado" (BRANDÃO, 2007, p. 182).

Para Celso Furtado e Amartya Sen, o crescimento econômico apresenta, inclusive, natureza diversa do desenvolvimento, o qual pressupõe o enfrentamento dos interesses da sociedade, ampliando a liberdade em todas as esferas da vida (FURTADO; SEN, apud BRANDÃO, 2007, p. 201).

"Somente crescer a economia nacional pode ser necessário para uma boa administração política de uma nação, mas não é suficiente para alterar a estrutura distributiva no Brasil”, pontuou Pochmann (POCHMANN, 2009, p.91). 
Quando se fala, portanto, em desenvolvimento, como "alargamento dos horizontes de possibilidades', se está falando necessariamente na construção de ações e políticas públicas”, na medida em que "o desenvolvimento significa, por sua própria natureza, um estado de tensão” (BRANDÃO, 2007, p. 200).

Amartya Sen já lembrou, inclusive, que economia e ética estão interligadas desde Aristóteles, mas a outra origem da economia, isto é, as questões logísticas, preponderaram, de modo que seria necessário reaproximar a economia e a ética, ou seja, promover o desenvolvimento com ética (SEN, apud SACHS, 2008, p. 13).

Seria fundamental, portanto, desenvolver ações planejadas que permitissem estratégias de desenvolvimento com vistas à implementação de pactos territoriais e reelaboração do "contrato social”, reconstruindo a coesão federativa.

Para Sachs, "o desenvolvimento, distinto do crescimento econômico, cumpre esse requisito, na medida em que os objetivos do desenvolvimento vão bem além da mera multiplicação da riqueza material", até mesmo porque "no contexto histórico em que surgiu, a ideia de desenvolvimento implica a expiação e a reparação das desigualdades passadas" (SACHS, 2008, p.13).

Segundo Brandão,

[...] para se pensar a repactuação federativa e a construção de um patamar mínimo de homogeneidade social, como pré-requisito de um reerguimento da escala nacional de desenvolvimento, será preciso utilizar as pulsões virtuosas de tamanhas assimetrias, mas de positiva criatividade e diversidade que a economia e sociedade brasileiras possuem. Certamente as questões da moradia, transporte, educação, saúde, segurança alimentar, entre outras, devem avançar do mero atendimento aos interesses materiais mais imediatos à construção de cidadania, ainda mais quando estão inseridas em uma estrutura urbana heterogênea, pobre, patrimonialista e predatória como a brasileira, em que a cidade acabou 'tornando-se agente de reprodução de desigualdades'. (...) A tarefa é inserir parcela crescente desse tecido social e urbano na cidadania plena, construindo a justiça social, garantindo o acesso a bens e serviços públicos, que seja educativa, isto é, que sua implementação represente um momento pedagógico da política pública de proteção social” (BRANDÃO, 2007, p. 212).

Assim sendo, a diferença desse enfoque não está fundamentalmente nos âmbitos regionais e locais, mas sim no espaço nacional, ou seja, na atuação do Estado nacional na reformulação econômica, institucional e espacial (FERNÁNDEZ, 2003, p. 59-60).

O desaparecimento do Estado com a globalização seria, por conseguinte, um mito:

O trabalho de Linda Weiss deu conta de que o mito do desaparecimento do Estado na globalização se baseia no desconhecimento da importância das capacidades estatais, e nas especificidades com que as mesmas se desenvolvem nos diferentes espaços (WEISS, apud FERNÁNDEZ, 2003, p. 62).

Dessa forma, seria a intervenção, e não a ausência do Estado, que contribuía para a inclusão positiva do país no cenário global. O caráter estratégico da intervenção estatal não seria dado pelo volume da intervenção, mas sim pela sua qualidade: "a questão central não seria assim o tamanho do governo, mas sim as atividades e métodos do 
governo" ${ }^{~}$ ou seja, a aplicação de políticas públicas em determinados campos temáticos (FERNÁNDEZ, 2003, p. 63-69).

Pochmann orientou, então, para 3 (três) aspectos que poderiam ser considerados no redirecionamento das políticas públicas:

\begin{abstract}
Inicialmente, o reconhecimento de que as políticas públicas de corte neoliberal foram responsáveis, em grande medida, pela manutenção do baixo ritmo de expansão econômica, em simultâneo às altas taxas de juros e aos processos de privatização do setor produtivo estatal e abertura comercial. (

Também cabe ressaltar o destaque às políticas públicas de natureza mais associadas à assistência à pobreza no Brasil. Na mesma linha das ações tradicionalmente conduzidas pelo poder público desde o início do século 20 , de fragmentação e pulverização de políticas com elevado custo operacional, o país estimula a criação de uma geração de iniciativas, cada vez mais de responsabilidade dos governos locais. (

Por fim, a ênfase das ações públicas direcionadas à busca da emancipação dos segmentos pauperizados. São iniciativas recentes e de menor participação na agenda governamental. Tratam-se fundamentalmente de medidas que rompem com a tradição da pobreza exclusivamente assistida quando introduzem novos conceitos como protagonismo e pertencimento social, e objetivos que almejam a condição de autonomia tanto política do público-alvo das instituições que assistem à pobreza quanto econômica, capaz de permitir o caminhar com as próprias pernas, deixando de depender exclusivamente de recursos públicos (POCHMANN, 2009, p. 97-98).
\end{abstract}

Pretendeu-se, com isso, constituir um novo padrão de políticas públicas de desenvolvimento, devidamente retratado na Declaração Sobre o Direito ao Desenvolvimento, adotada pela Resolução no 41/128 da Assembleia Geral das Nações Unidas, de 4 de dezembro de $1986,{ }^{2}$ que no $§$ 1o do seu artigo $8^{\circ}$ esclareceu sobre os serviços básicos aos quais o Estado deveria garantir o acesso, in verbis:

Os Estados devem tomar, em nível nacional, todas as medidas necessárias para a realização do direito ao desenvolvimento, e devem assegurar, inter alia, igualdade de oportunidade para todos no acesso aos recursos básicos, educação, serviços de saúde, alimentação, habitação, emprego e distribuição equitativa da renda. Medidas efetivas devem ser tomadas para assegurar que as mulheres tenham um papel ativo no processo de desenvolvimento. Reformas econômicas e sociais apropriadas devem ser efetuadas com vistas à erradicação de todas as injustiças sociais (USP, 1986) (destaquei).

Trouxe, também, outros aspectos do direito ao desenvolvimento:

1 STIGLITZ apud FERNÁNDEZ, Víctor Ramiro. Idem, p. 63: "La cuestión central no sería así el tamaño del gobierno, sino las actividades y los métodos del gobierno."

2 "Adotada pela ONU a Declaração sobre o Direito ao Desenvolvimento, em 1986, por 146 Estados, com um voto contrário (EUA) e 8 abstenções.” PIOVESAN, Flávia. 2 A Constituição dos Direitos Humanos e o Direito ao Desenvolvimento. Capítulo 6. Direito ao desenvolvimento: desafios contemporâneos. In:Temas de direitos humanos. São Paulo: Saraiva, 2002, versão digitalizada. 


\section{"Artigo 1}

§1. O direito ao desenvolvimento é um direito humano inalienável, em virtude do qual toda pessoa e todos os povos estão habilitados a participar do desenvolvimento econômico, social, cultural e político, para ele contribuir e dele desfrutar, no qual todos os direitos humanos e liberdades fundamentais possam ser plenamente realizados. \$2. O direito humano ao desenvolvimento também implica a plena realização do direito dos povos à autodeterminação que inclui, sujeito às disposições relevantes de ambos os Pactos Internacionais sobre Direitos Humanos, o exercício de seu direito inalienável à soberania plena sobre todas as sua riquezas e recursos naturais.

\section{Artigo 2o-}

§1. A pessoa humana é o sujeito central do desenvolvimento e deveria ser participante ativo e beneficiário do direito ao desenvolvimento.

\$2. Todos os seres humanos têm responsabilidade pelo desenvolvimento, individual e coletivamente, levando-se em conta a necessidade de pleno respeito aos seus direitos humanos e liberdades fundamentais, bem como seus deveres para com a comunidade, que sozinhos podem assegurar a realização livre e completa do ser humano e deveriam por isso promover e proteger uma ordem política, social e econômica apropriada para o desenvolvimento.

\$3. Os Estados têm o direito e o dever de formular políticas nacionais adequadas para o desenvolvimento, que visem ao constante aprimoramento do bem-estar de toda a população e de todos os indivíduos, com base em sua participação ativa, livre e significativa, e no desenvolvimento e na distribuição equitativa dos benefícios daí resultantes.

\section{Artigo $3^{\circ}$}

§1. Os Estados têm a responsabilidade primária pela criação das condições nacionais e internacionais favoráveis à realização do direito ao desenvolvimento.

\$2. A realização do direito ao desenvolvimento requer pleno respeito aos princípios do direito internacional, relativos às relações amistosas de cooperação entre os Estados, em conformidade com a Carta das Nações Unidas.

§3. Os Estados têm o dever de cooperar uns com os outros para assegurar o desenvolvimento e eliminar os obstáculos ao desenvolvimento. Os Estados deveriam realizar seus direitos e cumprir suas obrigações, de modo tal a promover uma nova ordem econômica internacional, baseada na igualdade soberana, interdependência, interesse mútuo e cooperação entre todos os Estados, assim como a encorajar a observância e a realização dos direitos humanos.

\section{Artigo $4^{\circ}$}

Os Estados têm o dever de, individual e coletivamente, tomar medidas para formular as políticas internacionais de desenvolvimento, com vistas a facilitar a plena realização do direito ao desenvolvimento. É necessária ação permanente para promover um desenvolvimento mais rápido dos países em desenvolvimento. Como complemento dos esforços dos países em desenvolvimento, uma cooperação internacional efetiva é essencial para 
prover esses países de meios e facilidades apropriados para incrementar seu amplo desenvolvimento.

\begin{abstract}
Artigo $5^{\circ}$
Os Estados tomarão medidas firmes para eliminar as violações maciças e flagrantes dos direitos humanos dos povos e dos seres humanos afetados por situações tais como as resultantes do apartheid, de todas as formas de racismo e discriminação racial, colonialismo, dominação estrangeira e ocupação, agressão, interferência estrangeira e ameaças contra a soberania nacional, unidade nacional e integridade territorial, ameaças de guerra e recusas de reconhecimento do direito fundamental dos povos à autodeterminação.
\end{abstract}

\title{
Artigo 6o
}

§1. Todos os Estados devem cooperar, com vistas a promover, encorajar e fortalecer o respeito universal à observância de todos os direitos humanos e liberdades fundamentais para todos, sem distinção de raça, sexo, língua ou religião.

§2. Todos os direitos humanos e liberdades fundamentais são indivisíveis e interdependentes; atenção igual e consideração urgente devem ser dadas à implementação, promoção e proteção dos direitos civis, políticos, econômicos, sociais e culturais.

§3. Os Estados devem tomar providências para eliminar os obstáculos ao desenvolvimento resultantes da falha na observância dos direitos civis e políticos, assim como dos direitos econômicos, sociais e culturais.

\begin{abstract}
Artigo $\mathbf{7}^{\mathbf{0}}$
Todos os Estados devem promover o estabelecimento, a manutenção e o fortalecimento da paz e segurança internacionais e, para este fim, deveriam fazer o máximo para alcançar o desarmamento geral e completo do efetivo controle internacional, assim como assegurar que os recursos liberados por medidas efetivas de desarmamento sejam usados para o desenvolvimento amplo, em particular o dos países em via de desenvolvimento" (USP, 1986) (destaquei).
\end{abstract}

Nos termos da Declaração adotada pela Organização das Nações Unidas, assim, o direito ao desenvolvimento contemplou 3 (três) dimensões centrais: Justiça Social; participação e accountability; e programas e políticas nacionais e cooperação internacional (PIOVESAN, 2002).

Segundo Piovesan, sendo a justiça social um componente central à concepção do direito ao desenvolvimento, "a realização do direito ao desenvolvimento, inspirado no valor da solidariedade, há de prover igual oportunidade a todos no acesso a recursos básicos, educação, saúde, alimentação, moradia, trabalho e distribuição de renda" (PIOVESAN, 2002).

O componentedemocrático (participaçãoe accountability) também seria essencial ao direito ao desenvolvimento, na medida em que competia aos Estados encorajar a participação popular em grupos de elaboração, implementação e monitoramento de políticas de desenvolvimento (PIOVESAN, 2002). 
Finalmente a cooperação internacional, indicando que o desenvolvimento, enquanto direito humano, apresentava dimensões nacional e internacional.

Dessa forma, concluiu Piovesan:

O direito ao desenvolvimento demanda uma globalização ética e solidária. No entender de Mohammed Bedjaqui: 'Na realidade, a dimensão internacional do direito ao desenvolvimento é nada mais que o direito a uma repartição equitativa concernente ao bem-estar social e econômico mundial. Reflete uma demanda crucial de nosso tempo, na medida em que os quatro quintos da população mundial não mais aceitam o fato de um quinto da população mundial continuar a construir sua riqueza com base em sua pobreza'. As assimetrias globais revelam que a renda dos $1 \%$ mais ricos supera a renda dos 57\% mais pobres na esfera mundial (PIOVESAN, 2002).

Em 1988, a Constituição da República Federativa do Brasil, segundo Miguel Reale, "optou por uma posição intermédia entre o liberalismo oitocentista, infenso a toda e qualquer intervenção do Estado, e o dirigismo estatal” (REALE, 2012, p. 179).

Eros Grau também chamou a atenção para o fato de que a dignidade da pessoa humana compareceu no referido texto constitucional duplamente: "no art. $\mathbf{1}^{\mathbf{0}}$ como princípio político constitucionalmente conformador (Canotilho); no art. 170, caput, como princípio constitucional impositivo (Canotilho) ou diretriz (Dworkin) - ou, ainda, como norma-objetivo" (GRAU, 2012, p. 194).

E seguiu esclarecendo:

Nesta sua segunda consagração constitucional, a dignidade da pessoa humana assume a mais pronunciada relevância, visto comprometer todo o exercício da atividade econômica, em sentido amplo - e em especial, o exercício da atividade econômica em sentido estrito - com o programa de promoção da existência digna, de quem, repito, todos devem gozar. (...)

Observe-se ademais, neste passo, que a dignidade da pessoa humana apenas restará plenamente assegurada se e enquanto viabilizado o acesso de todos não apenas às chamadas liberdades formais, mas, sobretudo, às liberdades reais (GRAU, 2012, p. 194-195).

Dessa forma, ao comprometer o exercício da atividade econômica com o programa de existência digna, viabilizando o acesso às liberdades reais, a dignidade da pessoa humana fundamentaria o direito de habitação.

Logo, a habitação estaria intimamente relacionada com o desenvolvimento, na medida em que poderia contribuir para a redução da pobreza por meio da formação de uma parte importante de uma nação ou do capital fixo de uma cidade, com um mercado imobiliário aquecido ajudando a impulsionar o crescimento econômico em outras áreas (HALL; MIDGLEY, 2008, p. 122).

Sachs lembrou, inclusive, que o objetivo supremo de um plano nacional seria o emprego, consistindo política complementar para o seu alcance a exploração de oportunidades de crescimento induzido pelo emprego, particularmente a "construção civil, especialmente programas voluntários de construção de casas populares com apoio 
governamental (casas populares construídas pelo povo)" (SACHS, 2008, p. 19).

Para o autor, a provisão de moradia decente para todos seria, certamente, um desafio para o desenvolvimento. "Daí a importância de políticas de moradias populares e, em particular, de esquemas baseados na autoconstrução assistida, nos quais as autoridades públicas se juntam aos esforços dos futuros moradores, cujo trabalho se constitui numa forma não monetária de poupança” (SACHS, 2008, p. 40).

Haveria, porém, o problema de definir a habitação adequada. Altos níveis de ocupação e espaço privado limitado poderiam, por exemplo, ser aceitáveis em algumas culturas, enquanto que espaços separados e maiores seriam valorizados em países muçulmanos, uma vez que, segundo Jenkins, as mulheres passariam a maior parte de seu tempo em casa (JENKINS, apud HALL; MIDGLEY, 2008, p. 123).

Não obstante essas controvérsias, Satterthwaite chegou a estimar que, em 1990, pelo menos 600 (seiscentos) milhões de pessoas nas áreas urbanas da América Latina, África e Ásia, viviam em habitações de qualidade tão ruim que constituía uma ameaça para a sua saúde e vida (SATTERTHWAITE, apud HALL; MIDGLEY, 2008, p. 124).

Ainda sobre as políticas de habitação, Hall e Midgley constataram que nas décadas de 1950 e 1960, os líderes de muitos novos Estados independentes começaram a construir conjuntos habitacionais em larga escala, destinados a corrigir as injustiças do colonialismo e funcionar como um símbolo de orgulho nacional, trazendo, subjacente, a crença de que o Estado deveria assumir a responsabilidade de abrigar seus cidadãos (HALL; MIDGLEY, 2008).

Os autores alertaram, também, que naquela época, muitos governos dos países em desenvolvimento, com base em tradições europeias, tentaram proporcionar habitação de alto padrão, ficando, contudo, sem dinheiro depois que apenas um pequeno número de unidades foram construídas, levando-os, por consequência, a tomar empréstimos para cobrir aqueles custos, até que, na década de 1970, ficou claro que tal estratégia era falha (HALL; MIDGLEY, 2008, p. 125).

Turner, então, sugeriu uma nova maneira de enfrentar o desafio da habitação: a autoajuda, segundo a qual ao Estado caberia apoiar os esforços dos pobres para construir suas próprias casas, em vez de tentar construir habitações de elevada qualidade, utilizando-se materiais produzidos no local, e, por isso, mais baratos, de modo a reduzir os padrões e os custos na habitação como meio de garantir moradia para um maior número de pessoas (HALL; MIDGLEY, 2008, p. 125).

Dessa forma, seriam 3 (três) as modalidades dos projetos habitacionais: sites-andservices (ao Estado caberia adquirir terrenos e conectá-los aos serviços básicos, como estradas, esgotos, abastecimento de água e eletricidade, vendendo-os, posteriormente, para as pessoas construírem suas próprias casas); core housing e upgrading (ao Estado caberia melhorar as favelas existentes ou assentamentos informais em vez de tentar realocar seus habitantes) (HALL; MIDGLEY, 2008, p. 126). 


\section{A HABITAÇÃO ENQUANTO CONCEITO DOTADO DE CARÁTER DE FUNDAMENTALIDADE}

Inicialmente, convém esclarecer sobrea aparente dicotomia entreos termos habitação e moradia, quando a doutrina os tem usado como sinônimos, na medida em que possuem "como elemento conceitual a preservação e o exercício do direito de ficar, viver ou de morar." (PANSIERI, 2012)

Não existe, na verdade, "nenhum erro daqueles que utilizam a mesma locução, quando citam um ou outro, quando não se faz menção ao direito em si, ou, ainda, quando não há discussão das consequências jurídicas que cada direito envolve" (SOUZA, 2013, p. 117).

Não obstante tal afinidade, Pansieri distingue a moradia da habitação:

[...] o Direito à Moradia está conectado com a pessoa, com os direitos da personalidade, fundado na garantia da dignidade da pessoa humana. Enquanto a habitação vem sendo utilizada para se referir às questões de cunho patrimonial ligadas ao morar. O que por sua vez não prejudica a utilização do Direito, mas pode causar alguns debates no seio de nossos tribunais. Como forma de melhor elucidar as diferenças entre o Direito à Moradia e o Direito à Habitação, cita-se como exemplo o princípio da transmissibilidade: que se traduz na alienabilidade e a hereditariedade dos direitos reais, que é adequada à habitação, porém inaplicável à moradia, porque neste caso, está se falando de direitos da personalidade, que por sua vez, são intransmissíveis em razão da infungibilidade dos direitos inatos à pessoa (PANSIERI, 2012).

Apresentada a afinidade e a distinção entre os termos moradia e habitação, alinhase o presente artigo à Declaração Sobre Direito ao Desenvolvimento da Organização das Nações Unidas, na qual, conforme já visto alhures, a habitação foi indicada como direito humano fundamental.

Por sua vez, a habitação encontra melhor definição na Observação Geral no 4 do Comitê de Direitos Econômicos, Sociais e Culturais da Organização das Nações Unidas, segundo a qual:

[...] significa dispor de um lugar onde se possa asilar, caso o deseje, com espaço adequado, segurança, iluminação, ventilação, infraestrutura básica, uma situação adequada em relação ao trabalho e o acesso aos serviços básicos, todos a um custo razoável (PANSIERI, 2012).

Já no ordenamento jurídico brasileiro, a habitação foi pela primeira vez tutelada na Constituição de 1891, ao mencionar que a casa seria asilo inviolável, seguida das Constituições de 1934, 1937 e 1946 nas quais foi garantido o direito de propriedade atrelado ao cumprimento da sua função social.

Até aí, a habitação aparecia apenas como componente secundário de outros institutos. "Porém foi com a Emenda Constitucional 26/oo que o direito à moradia foi elevado ao status de Direito Fundamental Social, sendo inserido no artigo 6o do referido diploma" (PANSIERI, 2012).

Sobre a fundamentalidade, Pansieri explica integrar a habitação a estrutura básica do Estado para a sociedade, em caráter vinculante: 
A ideia de fundamentalidade é característica própria dos Direitos Fundamentais e deriva da lição do jurista alemão Robert Alexy, lição esta recepcionada pelo tão importante jurista português J. J. Gomes Canotilho e que aportou no Brasil em diversos trabalhos, com especial relevo na obra de Ingo Wolfgang Sarlet. A referida ideia apresenta-se como proteção dos Direitos Fundamentais no âmbito formal e material. A fundamentalidade formal dos Direitos Fundamentais resulta de seu posicionamento no ordenamento jurídico, gerando efeito vinculante tanto para o Executivo, Legislativo quanto para o Judiciário, enquanto a fundamentalidade material está ligada à ideia de normas que constituem estruturas básicas do Estado e da Sociedade (PANSIERI, 2012).

Nesse contexto, o próprio Superior Tribunal de Justiça (STJ) registrou decisão ${ }^{3}$ reconhecendo a habitação com base no estreito vínculo com a dignidade da pessoa (PANSIERI, 2012).

Lado outro, há quem equipare a habitação às normas programáticas, ou seja, definidoras de programas, não aplicáveis ou exequíveis diretamente, conforme considerou Vieira de Andrade:

[...] direito à habitação, compreendido como direito a ter uma moradia condigna, constitui um direito a prestações, cujo conteúdo não pode ser determinado no nível das opções constitucionais e pressupõe uma tarefa de concretização e de mediação do legislador ordinário, não conferindo ao cidadão um direito imediato a uma prestação efetiva, já que não é diretamente aplicável, nem exequível (ANDRADE, apud PANSIERI, 2012).

Mas Pansieri explicou que a habitação pode ser caracterizada, também, como direito de defesa, valendo-se, para tanto, do ensinamento de Canotilho nos seguintes dizeres:

[...] quandoafirmamosqueo Direitoà Habitaçãoéum direitodocidadão, estamos a acentuar o caráter do direito; quando afirmamos que para assegurar o direito à habitação incumbe ao Estado programar e executar uma política de habitação inserida em plano de reordenamento geral do território e apoiada em planos de urbanização (...) estamos a salientar a dimensão institucional de um direito'. Portanto, resta afirmar-se a eficácia do Direito à Moradia, tanto como direito de defesa, quanto direito a prestações, sejam elas legislativas ou materiais culminando, quando preenchidos alguns requisitos, em direitos subjetivos. Constituindo-se a normas definidoras do Direito à Moradia, como normas de eficácia plena são 'as normas que produzem, desde o momento de sua promulgação, todos os seus efeitos essenciais, isto é, todos os objetivos especialmente visados pelo legislador constituinte, porque este criou, desde logo, uma normatividade para isso suficiente, incidindo direta e imediatamente

3 "DIREITO CIVIL. SUCESSÃO. DIREITO REAL DE HABITAÇÃO. COMPANHEIRO SOBREVIVENTE. POSSIBILIDADE. VIGÊNCIA DO ART. $7^{\circ}$ DA LEI N. 9.278/96. RECURSO IMPROVIDO. 1. Direito real de habitação. Aplicação ao companheiro sobrevivente. Ausência de disciplina no Código Civil. Silêncio não eloquente. Princípio da especialidade. Vigência do art. $7^{\circ}$ da Lei n. 9.278/96. Precedente: REsp n. 1.220.838/PR, Rel. Ministro SIDNEI BENETI, TERCEIRA TURMA, julgado em 19/06/2012, DJe 27/06/2012. 2. O instituto do direito real de habitação possui por escopo garantir o direito fundamental à moradia constitucionalmente protegido (art. 6o, caput, da CRFB). Observância, ademais, ao postulado da dignidade da pessoa humana (art. art. 1o ${ }^{\circ}$ III, da CRFB). 3 . A disciplina geral promovida pelo Código Civil acerca do regime sucessório dos companheiros não revogou as disposições constantes da Lei 9.278/96 nas questões em que verificada a compatibilidade. A legislação especial, ao conferir direito real de habitação ao companheiro sobrevivente, subsiste diante da omissão do Código Civil em disciplinar tal direito àqueles que convivem em união estável. Prevalência do princípio da especialidade. 4. Recurso desprovido." (STJ, REsp 1156744/MG, Rel. Ministro MARCO BUZZI, QUARTA TURMA, julgado em o9/10/2012, DJe 18/10/2012) (grifei) 
sobre a matéria que lhes constitui objeto'. Registrando-se que isto não significa a possibilidade de todos os cidadãos buscarem, via judiciário, a satisfação deste direito (ANDRADE, apud PANSIERI, 2012).

Considerando a natureza de direito de defesa, é que Nunes de Souza define a habitação como direito absoluto, "já que independe de qualquer pré-relação jurídica entre as partes, bastando a verificação da sua lesão por um ou mais indivíduos indeterminados, para o surgimento do direito de reparação dos danos causados" (SOUZA, 2013, p. 131).

O autor traz, ainda, a responsabilidade civil objetiva do Estado em relação à habitação, decorrente das normas internacionais de direitos humanos e da própria Constituição Federal de 1988 aqui já mencionadas, quando, por exemplo, edita leis inconstitucionais que geram prejuízos a uma determinada coletividade ou à sociedade, bem como em se tratando de omissão (SOUZA, 2013, p. 210-212).

Mas elucida que tal dever do Estado, relativamente à obrigação, não significa que

[...] se traduza em doar uma casa para cada indivíduo, pois os aspectos que envolvem o direito à moradia devem ser quanto às normas legislativas, que devem permitir o exercício do direito à moradia, bem como quanto à obrigatória intervenção estatal para regulamentar as atividades também do setor privado que se refiram à política habitacional, como a regulamentação de uso e acesso à propriedade imobiliária, ou, ainda, a facilitação por meio da concessão de uso especial para fins de moradia, como ocorreu com o advento da Lei Federal 10.257, de 10.07.2001, denominada Estatuto da Cidade (SOUZA, 2013, p. 214).

Dessa forma, a obrigação do Estado consiste em constituir uma legislação, um programa e um plano de ação de política habitacional, ao lado de instituições financeiras privadas intermediárias do Tesouro.

Isso para que "tais políticas públicas garantam o amplo acesso de todos ao mercado habitacional, fomentando planos e programas habitacionais com recursos públicos e privados para segmentos sociais desprotegidos economicamente" (SOUZA, 2013, p. 220).

O Brasil assumiu, nesse âmbito, o compromisso de, concretamente, efetivar a prerrogativa da habitação, por meio de medidas públicas que visam promover, proteger e assegurar a plena realização desse direito, ${ }^{4}$ em conformidade com o objetivo maior de desenvolvimento, com a satisfatória apropriação do espaço urbano pela população.

A seguir, a experiência brasileira da administração pelo poder público da questão da moradia com a participação popular no desenvolvimento de projetos habitacionais.

4 STF, RE 407.688-8, Rel. Min. Celso de Mello Filho, Revista Trimestral de Jurisprudência do Supremo Tribunal Federal, v. 200 , n. 1, abr./jun., 2007, p. 178. 


\section{A EXPERIÊNCIA BRASILEIRA DE PARTICIPAÇÃO POPULAR NAS POLÍTICAS PÚBLICAS DE HABITAÇÃO}

Este item cuida da participação popular na produção de moradia, enquanto política pública habitacional, na Grande São Paulo e na cidade de Natal, conforme pesquisas já referendadas em estudos acadêmicos. ${ }^{5}$

Os dados indicam que a partir da década de 1990, a "construção de novas moradias por sistemas de mutirão e de autoconstrução fazem parte de uma nova realidade" (RAMOS, 2007, p. 29), representando propostas de menor custo com vistas à qualidade de vida da população.

$\mathrm{Na}$ autoconstrução as moradias são produzidas pelo próprio habitante, com apoio do poder público na forma de uma planta padrão, de financiamento de materiais de construção e de assessoria técnica para construção (RAMOS, 2007, p. 40).

Já no mutirão habitacional, organizações comunitárias se dedicam a construir coletivamente as moradias, atuando o poder público como agente financiador, gerenciador e, também, executor.

O FUNAPS Comunitário, na qualidade de Fundo de Atendimento à População Moradora em Habitação Subnormal no município de São Paulo, contribuiu na gestão de Luiza Erundina de Sousa, entre os anos de 1989-1992, para a realização de políticas públicas de habitação popular, contando com a participação dos moradores na elaboração de projetos, gestão e execução dos empreendimentos.

Seu resultado, segundo a pesquisa, teria sido satisfatório, porquanto "verificouse que poucas mudanças foram feitas nas casas, em geral sendo interferências quanto ao acabamento das unidades, a execução de uma garagem ou a ampliação de mais um quarto" (RAMOS, 2007, p. 72).

Isso porque uma das características principais do programa foi a existência de vários tipos habitacionais, tendo em vista as particularidades do terreno e, especialmente, do morador, resultando na construção de 9.842 (nove mil oitocentos e quarenta e duas) habitações (RAMOS, 2007, p. 80).

A exemplo, o conjunto habitacional Madre de Deus, inaugurado no ano de 1995, em uma área de $75 \mathrm{om}^{2}$, na Rua Madre de Deus, número 769, no bairro da Moóca, na cidade de São Paulo.

No local, havia um cortiço, onde moravam 54 (cinquenta e quatro) famílias, sendo conhecido, à época, por "Inferninho", em razão da presença de desordeiros e criminosos (RAMOS, 2007, p. 81).

A situação daquelas pessoas era difícil:

5 Dissertação de mestrado de autoria de Leila Amanda de Carvalho Ramos, intitulada A participação popular no exercício das políticas públicas habitacionais como fator de influência no produto habitacional construído e apropriado, sob a orientação do Doutor Reginaldo Luiz Nunes Ronconi, junto à Faculdade de Arquitetura e Urbanismo da Universidade de São Paulo, em 2007. Dissertação de mestrado de Caliane Christie Oliveira de Almeida, intitulada Habitação Social: origens e produção (Natal, 1889-1964), sob a orientação da Professora Doutora Telma de Barros Correia, junto à Universidade de São Paulo, em 2007. 
O terreno do cortiço abrigava cerca de 240 pessoas, das quais 98 crianças, que viviam em quartos de $12 \mathrm{~m}^{2}$ distribuídos numa área de $10 \mathrm{X}_{50}$ metros. O uso dos dois banheiros e áreas de serviços era coletivo, sem privacidade ou higiene. Os banhos eram frios e a área de serviços continha apenas quatro tanques para uso de toda aquela gente (RAMOS, 2007, p. 81-82).

Em função disso, a organização dos moradores manifestou sua causa ao governo local, solicitando providências para um recomeço, sendo que, na ocasião, coube à prefeitura de São Paulo "fiscalizar o uso dos recursos, onde $10 \%$ da verba deveriam ser destinados à mão de obra, $4 \%$ à assessoria e $86 \%$ aos materiais e equipamentos" (RAMOS, 2007, p. 83).

Quando se fala que a participação popular em políticas públicas habitacionais tem por corolário a dignidade humana, é porque algumas mudanças importantes acontecem com a população envolvida:

No caso do Madre de Deus, foram realizados durante a execução das obras, cursos de alfabetização, de costura, cursos básicos para encanador, eletricista. As pessoas eram estimuladas em favor da união e da conscientização política, por meio de debates e palestras dadas pela própria comunidade. Outras atividades como assembleias, seminários, palestras, cursos, festas, ocorriam durante as obras, nas áreas livres do térreo dos edifícios (RAMOS, 2007, p. 86-87).

Satisfeitos, os moradores que participaram do aludido mutirão ainda hoje se orgulham de viverem num local construído por eles mesmos, passando para os filhos a perspectiva de obterem moradia própria por meio de políticas públicas habitacionais com participação direta das pessoas interessadas.

Outros projetos habitacionais na Grande São Paulo, apesar de não terem sido concluídos na ocasião da coleta de dados da referida pesquisa acadêmica, ajudam a ilustrar o presente trabalho. São eles: a Urbanização da favela Yamberê II e a produção de um conjunto habitacional vertical por empreitada, no município de Diadema; a Urbanização da favela Sacadura Cabral e a produção habitacional por empreitada, mutirão e autoconstrução, no município de Santo André; e o Reassentamento da área do Jardim Record Gleba $\mathrm{C}$ e a produção de um conjunto habitacional horizontal por empreitada, no município de Taboão da Serra (RAMOS, 2007, p. 89-90).

Os 3 (três) projetos incorporaram modelos de participação popular na construção de unidades habitacionais:

Destes, ainda pode-se mencionar como aquele com o melhor desempenho por parte da administração pública o caso da urbanização da favela Sacadura Cabral em Santo André, onde o enfrentamento das questões habitacionais e tentativa de envolvimento da população no desenvolvimento do processo foi mais explicitado, sendo perceptível uma melhor apropriação urbana após a execução dasunidades realizadasatravés daautoconstruçãoassistida. Verificou-sequeeste foi também o caso com melhor nível de organização da comunidade envolvida. $\mathrm{O}$ caso da urbanização da favela do Yamberê em Diadema pode ser classificado como ponto médio entre os casos estudados. Apresentou um nível interessante de organização da comunidade e foi pautado por relações abertas entre a prefeitura e a população quanto às discussões sobre as questões habitacionais. Por outro lado, em função da organização de sua produção, 
por meio de empreiteiras contratadas pela prefeitura, resultando na ausência da participação da população na construção das unidades, verificou-se significativo distanciamento dos futuros moradores na apropriação ao espaço urbano construído.

O projeto de reassentamento do Jardim Record em Taboão da Serra foi considerado o de menor importância quanto à questão da participação popular e de piores resultados urbanos e sociais. Neste caso observou-se um canal de diálogo prejudicado entre a população e a prefeitura municipal e praticamente a inexistência de uma comunidade organizada e empenhada em lutar pelos seus interesses, o que implica na omissão do direito garantido de participar e decidir junto à administração pública sobre as questões de interesse comum. A pouca representatividade da comunidade perante a prefeitura certamente dificulta profundamente o desenvolvimento de relações de ajuda - mútua. A postura da prefeitura acerca do projeto urbanístico e de arquitetura das unidades habitacionais remete-se a inúmeros outros projetos de massa desenvolvidos por tantas administrações anteriores no país, como por exemplo, os produtos tão criticados desenvolvidos pelo BNH (RAMOS, 2007, p. 159-16o).

Já em relação à cidade de Natal, a pesquisa acadêmica identificou 4 (quatro) momentos de atuação governamental no campo da habitação social, no período compreendido entre 1889-1964.

O primeiro momento, de 1889 a 1909, caracterizou-se pela preocupação do poder público apenas com a situação sanitária da cidade, não considerando como um problema de deficit habitacional a questão da falta de moradia aos migrantes e mendigos, reconhecendo-os como ameaça sanitária (ALMEIDA, 2007, p. 146).

De 1908-1913, o poder público admitiu existir um "problema de teto", relativamente à população sem recursos para adquirir a casa própria ou custear a locação de uma moradia (ALMEIDA, 2007, p. 147), mas também não considerou a situação como deficit habitacional, de modo que as obras públicas se limitaram ao embelezamento de fachadas.

A partir de 1930, a prefeitura local reconheceu a impossibilidade de a população de baixa renda ter moradia digna sem o auxílio governamental, sendo que no ano de 1932 foi iniciada a construção da primeira vila operária com apoio daquela municipalidade, a qual financiou sua atuação por meio dos "Institutos de Aposentadorias e Pensões (IAPs) e da Fundação da Casa Popular (FCP)” (ALMEIDA, 2007, p. 148/172-173).

É nesse cenário que a consciência coletiva desponta como importante fator para intervenções habitacionais ligadas à ideia de desenvolvimento, partindo da relação entre o poder público e a população.

Por fim, segundo os limites do recorte temporal da pesquisa acadêmica, o quarto e último momento de atuação governamental teve início noano de196o, quandoo problema das habitações precárias se mostrou um empecilho ao projeto de industrialização, na medida em que dava visibilidade ao estado de pobreza dos habitantes.

Nesse período, as soluções empregadas incluíram a participação popular:

[...] observou-se: a continuidade da produção de moradias pelos Institutos e Caixas de Aposentadoria e Pensões (IAPs), e pela Fundação da Casa Popular (FCP), inserindo-se nesse contexto a atuação da Fundação da Habitação Popular do Rio Grande do Norte (FUNDHAP) a partir de 1963; o incentivo à 
autoconstrução de moradias por meio da redução dos preços dos terrenos para facilitar a aquisição do lote; a ação em favelas; e a construção de conjuntos habitacionais instalados longe do centro da cidade, tendo como maior exemplo, a Cidade da Esperança. Cabe ressaltar que a criação de loteamentos e conjuntos habitacionais pela administração pública nesse quarto momento se diferencia das anteriores pelo fato de que os altos preços do solo, na zona urbana de Natal, já incidiam sobre a localização da moradia no espaço urbano. Para a concretização dessas ações consolidaram-se parcerias entre o governo municipal e estadual, e deles com agentes financiadores nacionais - Caixa Econômica Federal (CEF) e Fundação da Casa Popular (FCP) - e internacionais - USAID - além, do apoio dado pela Igreja Católica e da participação popular. Foram também criadas nesse sentido, instituições de âmbito estadual, como o Instituto de Previdência do Estado, em 1962 e a já citada Fundação da Casa Popular do Rio Grande do Norte (FUNDHAP), em 1963 (ALMEIDA, 2007, p. 149).

No contexto geral, não obstante a questão da habitação seja considerada de responsabilidade exclusiva do ente público, as moradias autoconstruídas ou edificadas por mutirões despontam como alternativas às favelas, ao mercado imobiliário informal, aos loteamentos irregulares e às diversas outras formas clandestinas de ocupação, na medida em que permitem a fiscalização e o controle da ocupação e do uso do solo das cidades.

"Nota-se, portanto, uma mudança do papel do Estado, que passou paulatinamente ao longo do século XX, de mero legislador para uma ação mais ampla no espaço de morar, como promotor direito de residências, sobretudo no campo da habitação social" (ALMEIDA, 2007, p. 220).

E, ainda que essa atuação estatal não tenha transformado a condição social, possibilitou, num balanço geral, melhorias de vida para as pessoas que foram contempladas, reduzindo o deficit habitacional nas áreas alcançadas.

\section{CONCLUSÃO}

Este artigo, escrito em 3 (três) itens (1 Antecedentes históricos da habitação enquanto aspecto do direito ao desenvolvimento no Brasil e no mundo; 2 A habitação enquanto conceito dotado de caráter de fundamentalidade; e 3 A experiência brasileira de participação popular nas políticas públicas de habitação), conclui que políticas públicas de habitação conduzidas pelo Estado constituem caminhos para o desenvolvimento.

Para tanto, foram estudados alguns aspectos do desenvolvimento, dentre eles o crescimento econômico como condição insuficiente para se erradicar, dentre várias mazelas, a pobreza.

Após considerar os abalos nos paradigmas econômicos, percebeu-se que o Estado desempenha papel determinante na trajetória rumo ao desenvolvimento, porquanto a ele compete melhor gerenciar e fomentar o desenvolvimento, interligando as regiões e fazendo observar o direito normatizado.

Viu-se, ainda, que para se alcançar o desenvolvimento é preciso garantir o acesso a serviços básicos, tal qual à saúde e à educação, como também à habitação.

Erigida à categoria de direito humano fundamental, a habitação, na verdade, 
facilitou, e muito, a busca pelo desenvolvimento, na medida em que, ao constituir dever do Estado, a obrigatoriedade de sua observância impele à realização de políticas públicas habitacionais, a exemplo da experiência brasileira já registrada nos anais históricos e acadêmicos.

\section{REFERÊNCIAS}

ALMEIDA, Caliane Christie Oliveira de. Habitação social: origens e produção (Natal, 1889-1964). Dissertação de Mestrado. São Paulo: Universidade de São Paulo, 2007.

ARNDT, H. W. Economic development: the history of an idea. Chicago: The University of Chicago Press, 1989.

BRANDÃO, Carlos Antônio. Território e desenvolvimento: as múltiplas escalas entre o local e o global. Campinas, SP: Editora da Unicamp, 2007.

FERNÁNDEZ, Víctor Ramiro. Desarrollo regional, espacios nacionales y capacidades estatales: redefiniendo el escenario global-local. Santa Fe, Argentina: Ediciones UNL, 2003.

GRAU, Eros Roberto. A ordem econômica na Constituição de 1988. São Paulo: Malheiros Editores, 2012.

HALL, Anthony e MIDGLEY, James. Social policy for development. Los Angeles, EUA: SAGE Publications, 2008.

PANSIERI, Flávio. Eficácia e vinculação dos direitos sociais: reflexões a partir do direito à moradia. São Paulo: Saraiva, 2012, versão digitalizada.

PIOVESAN, Flávia. Temas de direitos humanos. São Paulo: Saraiva, 2002, versão digitalizada.

POCHMANN, Marcio. Qual desenvolvimento? Oportunidades e dificuldades do Brasil contemporâneo. São Paulo: Publisher Brasil, 2009.

RAMOS, Leila Amanda de Carvalho. A participação popular no exercício das políticas públicas habitacionais como fator de influência no produto habitacional construído e apropriado. Dissertação de Mestrado. São Paulo: Universidade de São Paulo, 2007.

SACHS, Ignacy. Desenvolvimento includente, sustentável e sustentado. Rio de Janeiro: Garamond, 2008.

SOUZA, Sergio Iglesias Nunes de. Direito à moradia e de habitação: análise comparativa e seu aspecto teórico e prático com os direitos da personalidade. São Paulo: Editora Revista dos Tribunais, 2013. 
STF, RE 407.688-8, Rel. Min. Celso de Mello Filho, Revista trimestral de jurisprudência do Supremo Tribunal Federal, v. 20o, n. 1, abr./jun., p. 178, 2007.

UNIVERSIDADE DE SÃO PAULO (USP). Declaração sobre o Direito ao desenvolvimento, 1986. Disponível em < www.direitoshumanos.usp.br/index.php/Direito-aoDesenvolvimento/declaracao-sobre-o-direito-ao-desenvolvimento.html > Acesso em: 22 set. 2013. 